\title{
From Argumentation to Proof in Geometry Within a Collaborative Computer-Based Environment
}

\author{
Umberto Dello lacono ${ }^{1}$ (i)
}

Accepted: 16 May 2021 / Published online: 6 June 2021

(C) The Author(s) 2021

\begin{abstract}
This article is part of a wider research project that has the educational goal of supporting students in the production of conjectures, arguments and proofs, as well as promoting a move from the production of arguments expressed in colloquial registers to arguments expressed in literate registers. In this regard, we Giovannina Albano, Umberto Dello Iacono and Maria Alessandra Mariotti designed and implemented a digital educational environment that allows students to formulate and prove conjectures; three different working areas are available where students can work on a geometrical open problem sometimes individually, sometimes in collaboration. In this article, I report on an empirical study aimed at investigating the functioning of one of these areas, the 'Working with others' area, where small groups of students are expected to discuss and formulate a shared solution to a problem. The research question concerns if and to what extent the communication tools, specifically designed to foster students' collaboration, can promote the production of mathematically acceptable arguments. The qualitative data analysis shows that the 'Working with others' area seems to foster discussion within the group and can make students aware of their mistakes. Moreover, it can bring out some students' misconceptions and can provide useful information upon which the teacher can trigger fruitful discussions. However, this working area does not appear to foster a significant improvement of the production of mathematically acceptable arguments, produced by students in a collaborative and sharing mode. The integration of specific components within this working area seems to be necessary to support the student in moving from argumentation to proof.
\end{abstract}

Keywords Geometry · Argumentation · Proof · Computer-based environment · Collaborative learning $\cdot$ Collaborative script

Umberto Dello Iacono

umberto.delloiacono@unicampania.it

1 Department of Mathematics and Physics, University of Campania “L. Vanvitelli", Viale Abramo Lincoln, 5, 81100 Caserta, CE, Italy 
As widely shared in the mathematics education community, reasoning and proof as well as communication are recognized as key processes, necessary to learn mathematics with understanding. Students should be able to share and justify the processes and procedures used, providing adequate arguments to support or refute mathematical statements (NCTM, 2000). When students produce arguments, they elaborate and explain to themselves the concepts they are justifying (Baker, 2003) and this process can help them to integrate new information within existing cognitive structures (Chi et al., 1989). However, a collaborative approach based on the social and individual construction of knowledge (Vygotsky, 1980), encouraging the engagement of students, could promote the development of argumentative and communicative skills (Leitão, 2000; Andriessen et al., 2003; Lazarou et al., 2016; Albano \& Dello Iacono, 2018; Fujita et al., 2019). Students, interacting with peers, on the one hand, can compare their own ideas with those of others and, on the other, can explain and justify their reasoning to try to convince each other of the validity of their arguments.

Many scholars have investigated the potential offered by dynamic geometry for supporting design activities (Sinclair \& Robutti, 2012) to promote the production of arguments and proof by students. However, the combination of dynamic geometry with other digital environments could also support students in the formalization of proofs (Anderson et al., 1986, 1995; Miyazaki et al., 2017).

Our research is framed in this context. ${ }^{1}$ We assume the point of view that considers the mathematical proof as a specific case of argumentation (Mariotti et al., 1997), in agreement with Pedemonte (2007), who indicates proof 'as a particular argument' (p. 26), with Hanna (2014), for whom the argument 'includes mathematical proof as a particular case' (p. 406) and with Stylianides et al. (2016), who consider a proof as an argument accepted both by the community of mathematicians and by students of a given class community. We focus on geometry and try to exploit the potential of dynamic geometry software (DGS) for supporting students' design activities (de Villiers, 2004; Hoyles \& Jones, 1998; Laborde, 2000); at the same time, we take advantage of the potential of online platforms that offer tools for sharing and collaborating (Borba et al., 2016).

This research study is part of a wider project with the educational objective of supporting students in the production of conjectures, arguments and proof. The general research question concerns the design of a digital educational environment able to support students in such processes and, also, to foster a move from informal communication to a more formal one. We have, therefore, designed and implemented a computer-based educational environment that allows students to formulate and prove conjectures (sometimes individually, sometimes in collaboration interacting with each other and discussing ideas and opinions). In this article, I focus on a specific component (working area) of the educational environment specifically designed for supporting collaborative processes and I discuss its effect on fostering students' production of mathematically acceptable arguments.

In the following sections, I describe the conceptual background upon which our work is founded and the main theoretical assumptions that inspired both the

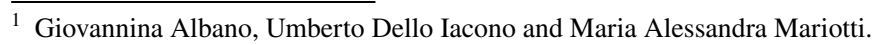


design of the digital environment and the analysis of the students' productions. I illustrate, therefore, the main characteristics of the digital environment and the description of the research methodology. Finally, I discuss the results obtained from an experiment involving upper secondary school students.

\section{Conceptual Background}

The controversial debate on argumentation and proof has been going on for decades and has involved many scholars (Mariotti, 2006; Mariotti et al., 2018; Stylianides et al., 2016). Some researchers identify heterogeneity between argumentation and proof, both from a social and epistemological point of view (Balacheff, 1988) and from a cognitive and linguistic one (Duval, 1991, 1995). More specifically, Duval (1995) regards argumentation as a natural form of reasoning arising from the need to justify a statement or claim. Argumentation involves both the production of reasons or arguments and the acceptability of the arguments produced. In mathematics, it is not enough to provide an argument; the second way of proceeding is essential, i.e. examining the acceptability of arguments according to a mathematical theory (axioms, theorems, definitions). In this regard, he highlights a structural gap between argumentation and proof, because in argumentation, inferences are based on content, while in proof, they follow a deductive scheme (data, claim and inference rules) and acceptability is guaranteed by mathematical theory. However, such a distance between argumentation and proof may be reduced as observed by Boero et al. (1996), who called this possibility cognitive unity:

During the production of the conjecture, the student progressively works out his/her statement through an intensive argumentative activity functionally intermingled with the justification of the plausibility of his/her choices. During the subsequent statement proving stage, the student links up with this process in a coherent way, organising some of the justifications ('arguments') produced during the construction of the statement according to a logical chain. (p. 113)

The production of arguments might promote the construction of a proof; if arguments supporting a statement are suitably reorganized according to a logical scheme and in relation to a specific theory, they can be transmuted into a proof. In other words, any conjecture has to be rebuilt into a mathematical theorem, that is the combination of a statement, a proof and a theory that gives sense to them (Mariotti et al., 1997).

Without neglecting the differences between arguments and proof, we assume that the link among arguments produced by students in support of their conjectures and proofs of such conjectures should be exploited from a didactic point of view. We will refer to this assumption as the cognitive unity hypothesis. According to this hypothesis, a proof may therefore be more easily accessible to the 
student, if it is related to a previous activity of argumentation aimed at supporting the production of a conjecture. In this regard, learning activities that aim to encourage the production of conjectures, and consequently arguments, by students can foster the rise of proofs.

In this sense, on the one hand, open problems (Arsac et al., 1991; Boero et al., 1999; Hadas et al., 2000; Pedemonte, 2008; Miyazaki et al., 2017) that require the formulation of a conjecture for their resolution are extremely effective in introducing the concept of proof. On the other, the production of arguments is certainly favoured by collaborative activities, in which students have to explain their own ideas, take into account those of others and compare them to reach a shared conclusion. Thus, interaction among students through group work on collaborative activities has been promoted with this intention.

It is well known, however, that students, when working collaboratively, are not always effective in producing arguments (Kuhn et al., 1997; Mandl et al., 1996). Indeed, collaboration should be properly designed in order to be effective and promote learning. In this sense, several studies have shown how collaborative scripts (e.g. King, 2007) can facilitate the development of argumentative competence (Andriessen et al., 2003; Marttunen \& Laurinen, 2001) and support students by scaffolding students' engagement in educational activities at a higher level than their actual level of competence (Stegmann et al., 2007). The script construct was born in cognitive psychology and identifies an internal memory structure corresponding to a sequence of actions that define a well-known situation (Schank \& Abelson, 1977). In the educational context, the script is externally imposed and regulates the sequence of roles and actions, in order to foster specific cognitive, socio-cognitive and metacognitive processes (King, 2007). External scripts are widely used in computer-based environments (Weinberger et al., 2009), in which pre-structuring and regulating social and cognitive processes are required.

As far as collaborative activities are concerned, Weinberger et al. (2007) identify the following as essential dimensions in the process of knowledge construction in computer-supported collaborative learning (CSCL) environments: the epistemic dimension, the argument dimension and the dimension of social modes of co-construction. The epistemic dimension describes arguments as steps forward in problem solving. It answers the question: how do the students' arguments contribute to solving the task? The argument dimension refers to the formal criteria for constructing arguments. It answers the question: how do students construct formally acceptable arguments? The dimension of social modes of co-construction describes how students interact with each other. It answers the question: how do students operate on the reasoning of their peers involved in the collaborative activity?

In this regard, Weinberger and Fischer (2006), in their theoretical framework, identify three types of components within a computer-based script: epistemic script components, which help students focus on the task and support them in finding appropriate solving strategies; argumentative script components, which support the construction of formally acceptable arguments; social script components, which foster interactions among students in order to promote the production of arguments and counter-arguments that is unlikely that they would produce spontaneously. Script components can affect each of the script dimensions. However, concerning 
the argumentative knowledge construction, they show that each script component has positive effects on its respective dimension. Initially, the script is external to the student, but it is expected that, over time, it will be internalized through practice, in a Vygotsky perspective of learning, first socialized and then internalized.

As mentioned above, in moving from a practice of argumentation to the construction of proofs, students also have to take into account the logical constraints required by the deductive structure of a proof and the reference to theorems or definitions, i.e. the available elements of the theory (Mariotti, 2006). In this regard, Sinclair et al. (2016) indicate definitions (in particular of a triangle and a quadrilateral) as a significant aspect, both from the educational and from the research point of view. As a matter of fact, students often do not know how to use definitions in the construction of a proof, because they do not understand the latter's theoretical meaning in depth (Freudenthal, 1973; Mariotti \& Fischbein, 1997; Moore, 1994).

The difficulties that students encounter in dealing with definitions are accompanied by difficulties in the appropriate use of language. More specifically, students have difficulties in moving from colloquial registers to literate registers. By register, we mean a linguistic variety based on use (Halliday, 1985). It is possible to distinguish between colloquial and literate registers. Colloquial registers are typically used in everyday communication, almost always in spoken communication, but they can also be used in some written communications, e.g. text messages. The use of a colloquial register is more effective in the early stages of the learning process. Literate registers, instead, are typically used in academic communication and characterize academic discourse - they are necessary to formulate proofs correctly consisting of deductive chains (Ferrari, 2004). This move from colloquial registers to literate ones becomes crucial when a student has to move from arguments to proofs. However, such a move is not spontaneous; rather, as we assume, it should be intentionally fostered through specific educational activities.

\section{The Computer-Based Environment}

In this section, I first describe the principles that inspired the design of the computer-based environment and then I describe the working areas that compose the environment, focusing on their fundamental characteristics and properties.

\section{The Design Principles}

Based on the conceptual background described in the previous section, we have formulated the following principles (Albano et al., 2021), on which the design of the computer-based environment should be based:

P1: support students in the solving of conjecturing open problems, that is supporting them in producing conjectures and constructing their proof;

P2: support a move from producing arguments expressed in colloquial registers to arguments expressed in literate registers. 
Both principles $\mathrm{P} 1$ and $\mathrm{P} 2$ are consistent with the cognitive unity hypothesis. $\mathrm{P} 1$ specifically takes into account the basic general didactic assumption, i.e. introducing students to mathematical proof and proving can be fostered through activities that ask for conjectures. P2 takes into account the assumption of potential continuity between argumentation and proof.

However, the careful design of educational activities and the necessary mediation of the teacher are crucial aspects to be taken into account in order to use technology effectively in the mathematics learning process (Drijvers, 2012; Trouche \& Drijvers, 2014). From this point of view, a DGScan support teachers in design activities (Sinclair \& Robutti, 2012). However, many authors (Chevallard \& Ladage, 2009; Arzarello et al., 2012; Laurillard, 2013; Xiao et al., 2018) highlight that success in learning is not a result of the choice of tools to be used nor of the theoretical frame of reference, but rather of the need for effective design that integrates learning theories and specific domain frameworks. In this stream of research, some studies in mathematics education have considered the possibility of integrating a DGS within other digital environments. For example, many researchers have focused on the formalization of proofs, with the aim of designing environments able to support students in the creation of step-by-step proofs, for example by using flowcharts (Anderson et al., 1986, 1995). Other researchers, with particular reference to geometry, have designed web environments that allow secondary school students to construct different steps of a proof by dragging single elements (side/angle/ triangle) of a diagram within a flowchart (Miyazaki et al., 2017).

Starting from these considerations, and according to the two principles P1 and P2 stated above, we have combined different digital environments to exploit the potential synergy between them.

\section{The Design of the Digital Environment}

Inspired by the above principles, we have designed a digital environment that integrates a DGS (GeoGebra) into the Moodle platform (Albano \& Dello Iacono, 2019a). The aim, on the one hand, is to promote the move from spontaneous arguments to mathematical proofs and, on the other, to develop students' awareness of the meaning and specificity of a mathematical proof with respect to spontaneous arguments.

In this direction, the digital environment was designed according to two design lines:

The first line of design aims at fostering cognitive unity. On the one hand, we provide students with a rich and stimulating space where they can formulate free conjectures and arguments and, on the other, a context to problematize their linguistic choices and produce mathematical arguments and proofs. In this regard, we designed a digital device, called Digital Toolkit for Proof (DTP) (Albano et al., 2019, 2021), implemented with GeoGebra and integrated within the Moodle platform (Albano \& Dello Iacono, 2019b). It aims to support the student in moving from colloquial registers to literate ones, providing her with theoretical elements (to which she can refer to prove her conjec- 
ture) and digital tiles representing linguistic elements that the student can drag to build her proof (for more details, see the final section).

The second line of design promotes collaboration among students in order to encourage the production of conjectures and arguments that might not appear without discussion with others. Indeed, through collaborating, students can exchange different representations of geometric objects and negotiate with one another to reach collective definitions of particular geometric objects (Fujita et al., 2019).

Following these two design lines, the research project envisages the design of three working areas, which have different didactical functionalities, i.e. characteristics and/or methods of use (Cerulli et al., 2005) and accordingly might promote different types of interaction among students:

- working alone: students, individually, try to solve the geometric problem;

- working with others: students, provided with communication tools, discuss their solutions within a small group and then formulate a shared answer;

- working alone and with others: the students first work individually to solve the geometric problem, then they negotiate with one another in small groups and, finally, the groups interact and negotiate with one another.

According to our research aims, we intend to explore the combination of these three areas that is expected to create a context of potential continuity between the arguments produced in support of a conjecture and the construction of its proof, i.e. to exploit the possible continuity between argumentation and proof (Pedemonte, 2002, 2007).

As opposed to the 'Working alone' area (in which the student works individually), the 'Working with others' and 'Working alone and with others' areas were designed as computer-based collaborative scripts (King, 2007; Weinberger et al., 2009) with the aim of fostering interaction among students who construct and post their arguments, but who also receive and read arguments from the classmates, evaluate them and respond, building counter-arguments. In other terms, each area involves and combines differently the epistemic, argumentative and social script components (Weinberger \& Fisher, 2006). Thus, the 'Working alone' area, which includes primarily argumentative but not social components, can be compared with the 'Working with others' area (which privileges social components), with the objective of exploring separately the contribution of the different combination of the argumentative and the social components of the scripts. The analysis of students' actions and interactions within these working areas can lead to understanding how the argumentative and the social components may influence the production of formal arguments. In order to understand, on the one hand, the effectiveness of DTP device and, on the other, the effectiveness of collaboration, we integrated the DTP device only in the 'Working alone' and 'Working alone and with others' areas, but not in the 'Working with others' area.

In this article, I focus on the 'Working with others' area. More specifically, the aim of this article is to deal with the following research question: to what extent is 

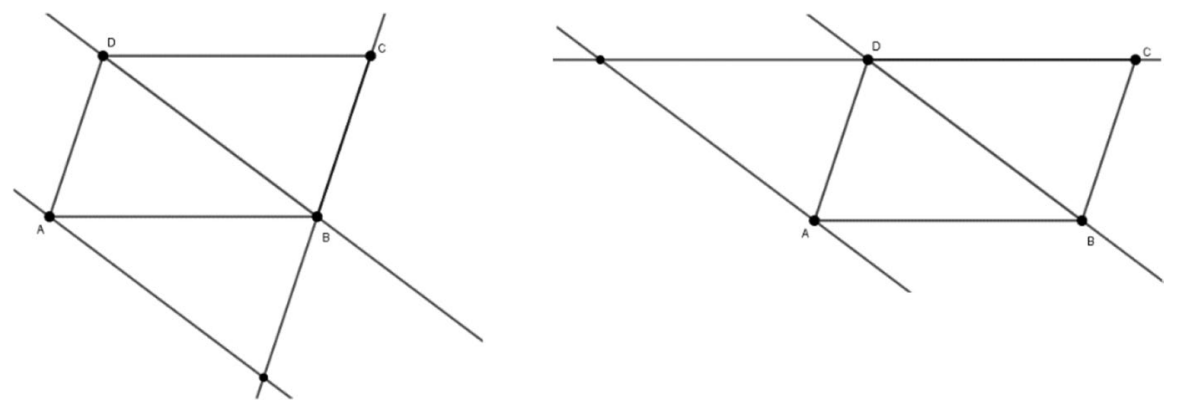

Fig. 1 Possible configurations

the 'Working with others' area by itself, by means of stimulating collaboration and discussion within the group, able to foster the production of mathematically acceptable arguments, co-constructed in a collaborative and sharing mode?

\section{Method}

In order to foster students' moving from spontaneous argumentation to mathematical proofs, we designed and implemented a specific environment, starting from an open problem concerning quadrilaterals. I experimented this specific environment with 60 students from four different high schools (9th-10th grade). The experiment was carried out at school and students worked in the computer lab, each with their own PC. Of these 60 students, 18 worked on the 'Work alone' area, 20 on the 'Working with others' area and 22 on the 'Working alone and with others' area. The researcher was involved in the experiment and provided technical support regarding the use of the platform. The students were not trained for this experience. According to the teachers' reports, the students were not used to collaborate in group activities; they were rarely involved in argumentative activities and general discussions. They were familiar with GeoGebra, but had never worked with online platforms.

\section{The Implementation of a Specific Computer-Based Environment}

In this section, I describe the main features and the design logic of the 'Working with others' area. According to the design principle P1 (see the beginning of the previous section), the following conjecturing open problem was identified:

Given a parallelogram $\mathrm{ABCD}$, draw a parallel to the diagonal BD passing through one of the other vertices. Extend one of the sides of the parallelogram that does not contain that vertex until it meets the drawn parallel. Which quadrilaterals can be identified in this figure? What kind are they? Please justify your statements.

Starting from the construction of the parallelogram ABCD, the student, if she draws the parallel to BD passing through A, can proceed in two different ways: she 
can extend BC, obtaining the construction shown on the left of Fig. 1, or extend CD, obtaining the construction shown on the right of Fig. 1. In both cases, two parallelograms and one trapezoid can be identified.

In order to identify the quadrilaterals, and thus deduce their type and name from their characteristics, students could/should refer to the mathematical theory of quadrilaterals, including the definition of parallelogram and that of trapezoid.

Students were divided into pairs and the collaborative activity, implemented in the Moodle platform, involves the following three phases, each phase characterized by a given task.

Task 1: each student is required to construct a GeoGebra figure, by using a 'blank' GeoGebra page, integrated within a Moodle Page, where only the commands needed for the required construction are available.

Task 2: Once the figure is constructed, in the forum 'Let's agree', the student is asked to upload the screenshot of the constructed figure and to report her conjecture regarding the identification and classification of the quadrilaterals and its justification. After doing this, the student can see her partner's GeoGebra construction, conjecture and justification. In this respect, 'Let's Agree' forum (students have access to it, but each group has access only to its own) is implemented as Moodle's Question and Answer forum, which allows each student to view their partner's postings only after they have posted their own. In this way, individual posts are encouraged, not conditioned by others.

Task 3: after posting her answer, the student can view the post of her partner, with whom she will have to discuss in order to achieve a common answer.

Task 4: a student of the group (named 'Spokesperson' within the group) reports the agreed common answer on the same forum 'Let's agree'.

According to the framework of Weinberger and Fischer (2006), Tasks 1 and 2 are designed primarily as epistemic script components, because they focus the student's attention on problem solving. Instead, Task 3, stimulating interaction and discussion within the group, is designed primarily as a social script component.

\section{Data Collection and Analysis Criteria}

Data was collected through the Moodle platform and analyzed mainly from a qualitative point of view. I analyzed the students' productions, comparing individual productions (Task 2) with those shared within the group (Task 4), i.e. before and after the discussion phase (Task 3). The purpose was to understand the effects of Task 3 on the production of arguments in support of a statement or conjecture. I have looked for evidence of the production of arguments and of their evolution towards proof, such as the appropriate use of mathematical terms and properties, and the use of a deductive structure for arguments. The use of causal conjunctions allows the student to construct an argument which can be transformed into a deductive one. However, such a deduction is only mathematically acceptable if it contains explicit references to relevant geometric properties or definitions. 
According to the conceptual background section, in particular to the definition of mathematical theorem as a triplet composed by statement, proof and mathematical theory, I have selected the following criteria for qualitative analysis of the students' productions:

- do they include the formulation of statements, expressed mathematically?

- do they include arguments in support of the claims, through the use of causal conjunctions (e.g. because, by construction)?

- do they refer to definitions (e.g. of parallelogram or trapezoid) or to specific geometric properties (e.g. parallel sides, congruent sides)?

\section{Data Analysis and Findings}

In this section, starting from the criteria identified above, I present a qualitative analysis of the students' productions during their activities in "Working with others" area. Although a statistically significant quantitative analysis is not possible, I provide some percentages about the distribution of students' answers. This will give an idea of the significance of what has been observed.

In Task 1, fourteen out twenty students involved in 'Working with others' area constructed a correct figure, of whom 11 produced one that could be traced back to the configuration on the right side of Fig. 1. Two of the students composed an incorrect figure (the most common error consists in not correctly drawing the parallel to the diagonal of the parallelogram, passing through the vertex), while only one did not construct any figure at all. Although not expressly required, almost all of the students assigned labels to points of the GeoGebra construction. In particular, eleven students assigned labels to all the points of the construction, i.e. the vertices of the initial parallelogram and the point of intersection between the line parallel to the diagonal and the extension of the side. Seven students added labels to all the points except the point of intersection, while only two students did not assign any labels. It seems, as can be seen in the following, that the need for discussing within the group led most students to assign labels to points of the GeoGebra construction, in order to be able to communicate clearly and unambiguously. As far as Task 2 is concerned, a majority of students did not provide any justification in support of their conjectures, despite the explicit request within the task to do so: Please justify your statements.

I compare the students' productions in Tasks 2 and 4, i.e. before and after the collaboration (Task 3). A qualitative analysis of the students' transcripts was carried out following the criteria defined earlier, in the previous sub-section. For each of the cases discussed, I provide a table showing first the individual answers (produced in Task 2), then the discussion within the group (generated in Task 3) and, finally, the shared answer within the group (related to Task 4).

I discuss in detail the productions of some groups, as prototypical examples of categories identified by analyzing the productions of all students:

the case of Ilenia and Claudia: in the shared answer (Tasks 3 and 4), they produced a new text, better than Ilenia's individual one, but worse than Claudia's; 
the case of Luigia and Samantha: the students seemed to imitate a teacher-student interaction by focusing on 'mistakes' and 'assessments';

the case of Simon 3 and Elbusy: no discussion started in Task 3 and the shared answer reported both the individual conjectures;

the case of Conad and Forever33: Forever33 tried to correct the partner's mistakes by behaving like an expert and, finally, without any agreement, he presented his answer as shared and attached his figure and that of the partner, suitably adjusted.

\section{The Case of Ilenia and Claudia: a New Text}

Both Ilenia (Table 1, \#1, Fig. 2) and Claudia (\#3, Fig. 3) correctly constructed their figures with GeoGebra. However, unlike Ilenia, Claudia assigned letters to the points of her GeoGebra construction. In her individual answer (\#2), Ilenia identified only two parallelograms and did not argue, although she used mathematical terms and a casual conjunction in her answer. The causal conjunction because introduced an argument based only on the observation of the figure and on the perceptive recognition of certain properties. Ilenia perceptively recognized that a new quadrilateral had been generated, that it was still a parallelogram, but she did not theoretically justify what had been observed. She did not provide any geometrical argument, i.e. based on the properties of the figure and, consequently, on the definition.

Claudia, on the other hand, identified all the quadrilaterals, i.e. two parallelograms and a trapezoid (\#4). For one of the parallelograms, she justified using parallelism and congruence of the opposite sides; for the second one, she only explained how it was constructed, while for the trapezoid, she highlighted the parallelism between two sides. The clarity of her argument seems also due to her choice to assign letters to the points of the GeoGebra construction, which allowed her to refer to segments, straight lines and polygons in an unambiguous manner.

The result obtained as a shared answer (\#9, Fig. 4) is a new text, posted by Ilenia. Such a text, however, was not really a combination of the previous two. Indeed, some information given by Claudia is absent (e.g. the congruence of segments $\mathrm{AB}$ and $\mathrm{DC}$ and segments $\mathrm{AD}$ and $\mathrm{BC}, \# 4)$. The students seemed not to realize that the answer formulated was not comprehensible, i.e. what Ilenia wrote in the shared answer had no correspondence with the included figure. Indeed, Ilenia posted her GeoGebra construction (without labels), while the text referred to points' labels that did not appear in the construction.

In formulating the new text, Ilenia improved a lot compared with what she had written on her own (\#2), even if the new text was less precise than the one produced by Claudia. Sharing, therefore, favoured Ilenia, but not Claudia who, by agreeing with the one proposed by Ilenia (\#8), accepted a text that seems not to improve her individual production (\#3, Fig. 3, and \#4). A negotiation process between the two students is evident: Claudia accepted Ilenia's reworking of her text, in particular, the replacing of the term diagonal with bisector (\#7 and \#9, Fig. 4), which neither she nor Ilenia had used before. The meaning of the word 'bisector' is adapted to express 


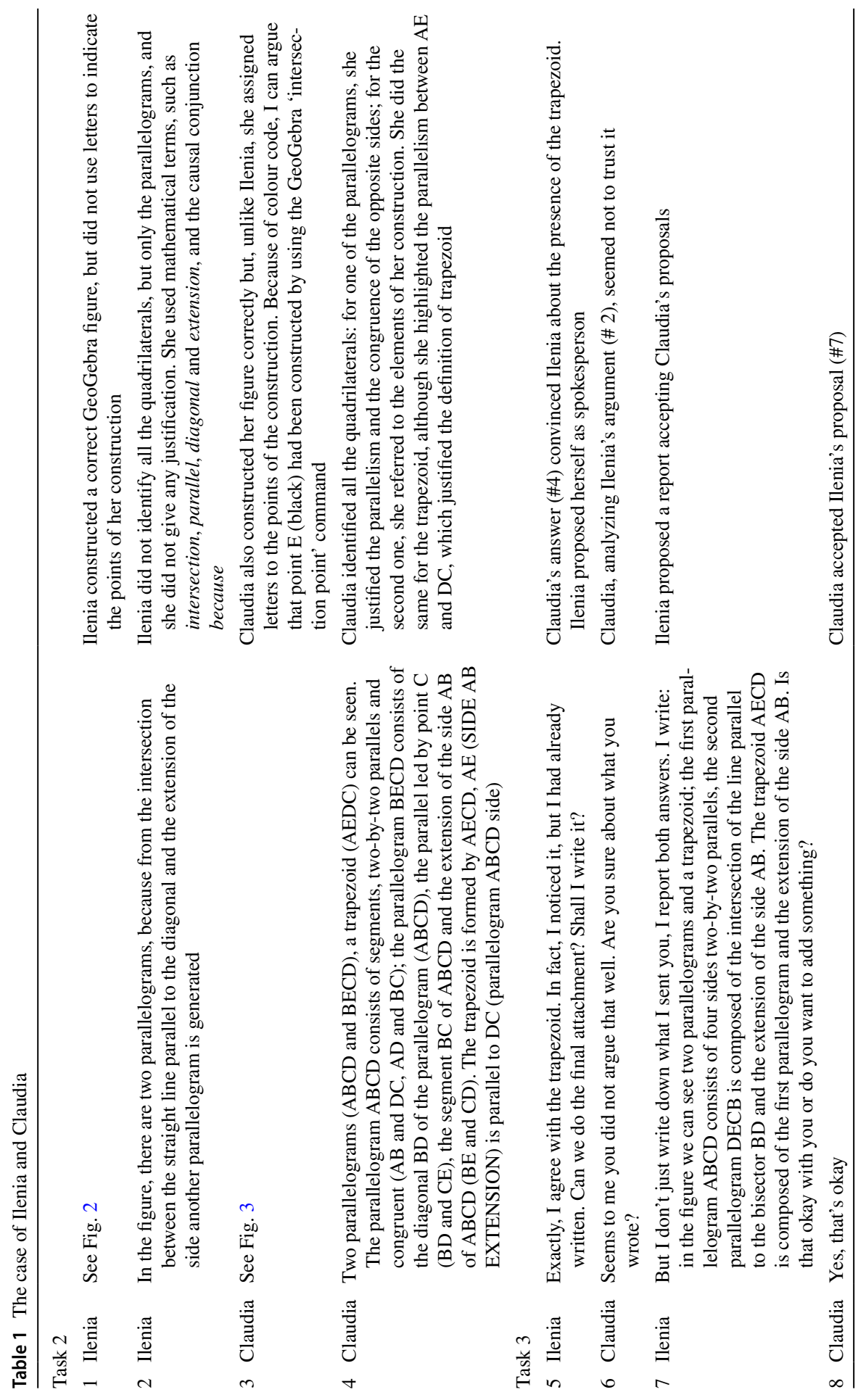




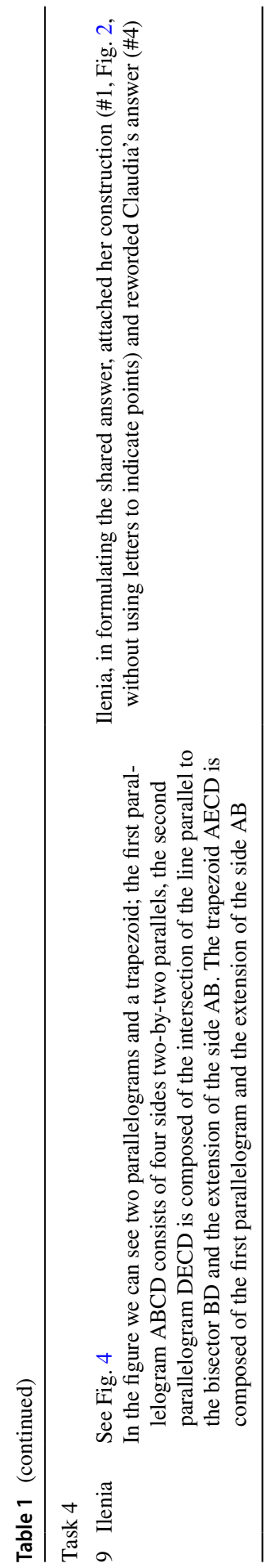


Fig. 2 Ilenia's GeoGebra construction

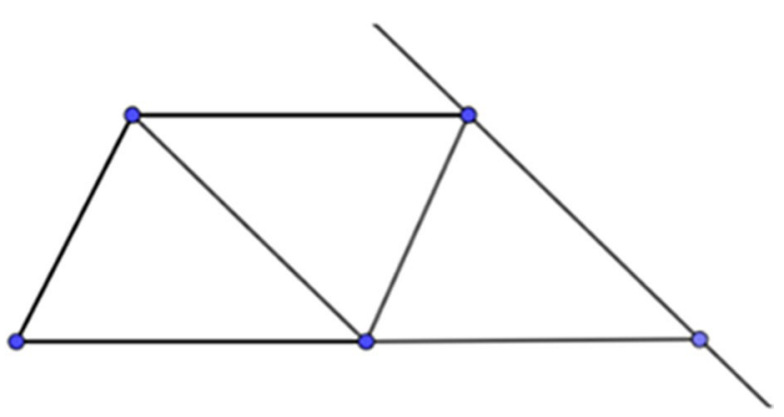

the property of dividing an angle into two parts, neglecting the fact that these two parts must be equal.

\section{The Case of Luigia and Samantha: Let's Choose My Answer}

Luigia constructed a figure that does not respect the indications given (Table 2, \#10, Fig. 5) and did not identify all the quadrilaterals, but only one parallelogram and the trapezoid BEDC (\#11). The latter was identified due to the construction mistake. However, she justified her answer. Samantha, on the other hand, constructed her figure correctly (\#12, Fig. 6). Moreover, she justified her answers with arguments referring to the definitions of a parallelogram and a trapezoid, while also making use of terms belonging to a literate mathematical register.

In the discussion following Samantha's post, Luigia (\#15) realized her mistake (\#10. Figure 5) and remarked the great "accuracy" of her partner's argument (\#13). The students agreed, therefore, to post Samantha's answer (\#16-\#17), since they considered it to be "very accurate" compared with that of Luigia. Samantha, as spokesperson, presented the answer she formulated individually and the figure she constructed (\#18, Fig. 7).

The students, rather than communicating with each other, seem to focus on "mistakes" and "assessments" (\#14, \#15, \#17), perhaps imitating the teacher's feedback. As mentioned above, the two students (like everyone else involved in the experiment) were not used to collaborating in class: they seemed not to be

Fig. 3 Claudia's GeoGebra construction

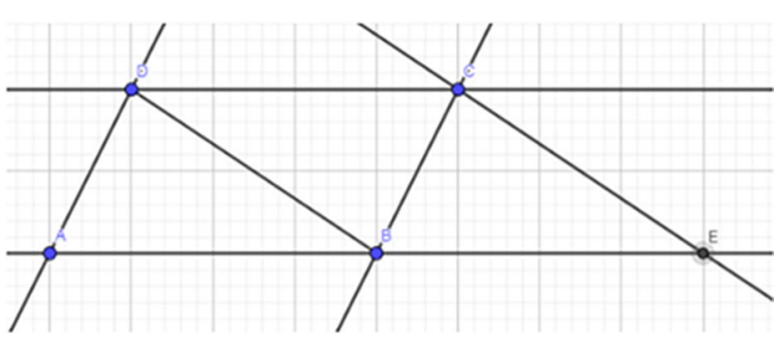


Fig. 4 Ilenia and Claudia's construction

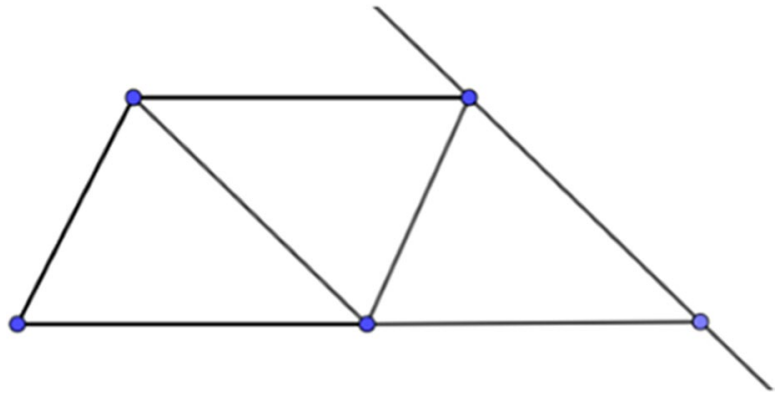

able to take advantage of collaboration. Instead, they seemed to have had great experience of the student-teacher interaction and conformed their communication to such kind of interaction.

\section{The Case of Simon3 and Elbusy: No Discussion and Both Conjectures}

Simon3 correctly constructed his figure (Table 3, \#19, Fig. 8) and assigned the letters to the points of his GeoGebra construction, even though he drew both diagonals of the parallelogram. However, the student did not identify all quadrilaterals, nor provide any justification (\#20).

Elbusy made a mistake in his GeoGebra construction (\#21, Fig. 9), but identified and justified what he saw using mathematical terms, although with some imprecision. The interaction between the two students was almost completely absent: they seemed to be aware of the differences between their GeoGebra constructions, but even though Simon3 stated that his partner's figure was wrong, no discussion started. All this led Elbusy (\#24) to:

not attaching any figure, probably aware of the mistake committed, pointed out by his partner;

producing as "common text" exactly his text (\#22) without any reworking, and signed by him, to which he adds the summary answer given by the partner (see the last sentence in \#24).

\section{The Case of Conad and Forever33: I Report My Own Conjecture}

Conad constructed his GeoGebra figure incorrectly (\#25, Fig. 10). He extended the side $\mathrm{AB}$, but the line passing through $\mathrm{C}$ (actually the segment EF in his construction) is not parallel to the diagonal BD. He identified only the initial parallelogram (\#26), but did not identify either the trapezoid ADCF or the trapezoid BDCF, which actually would have been a parallelogram in the correct GeoGebra construction. He also focused on triangles, but only identified two of them. He did not provide any arguments to support his conjectures. Forever33, on the other hand, correctly constructed his GeoGebra figure (\#27, Fig. 11). However, this 


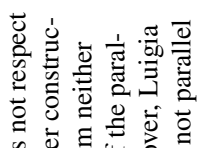

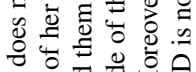
.$=0$

要

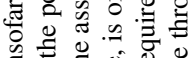

至

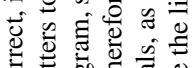

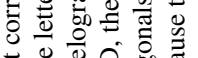

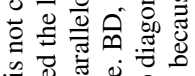

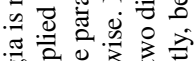

.

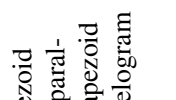

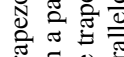

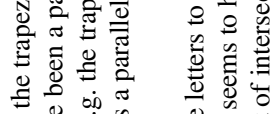

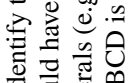

흠

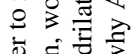

ฮี

可

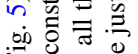

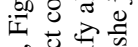

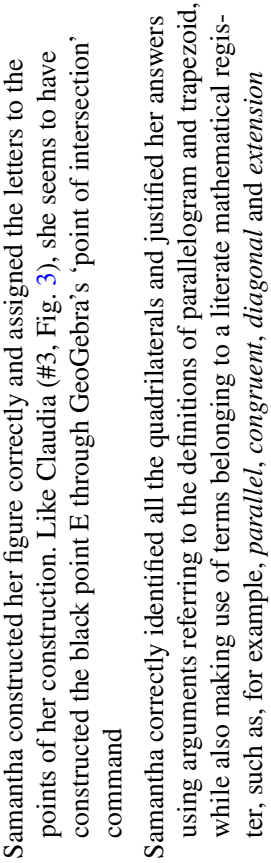

$\stackrel{\overline{0}}{\circ}$

\#苛节

.0.00

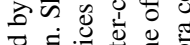

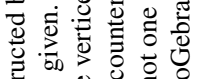

๑ै

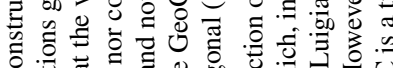

ర윯

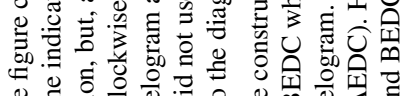

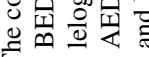

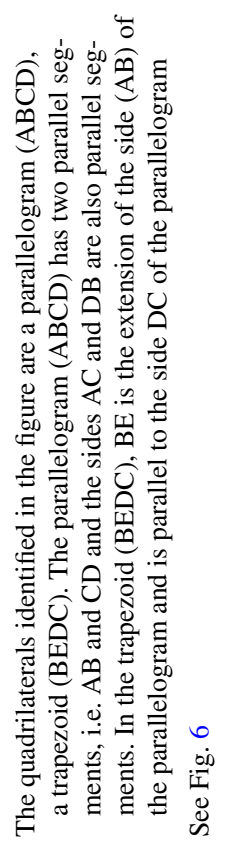

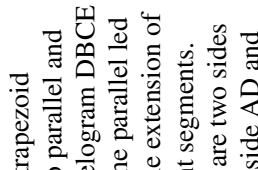

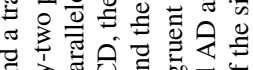

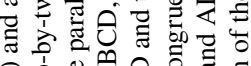

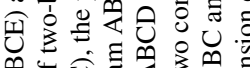

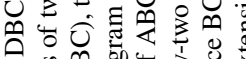

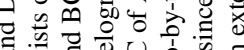

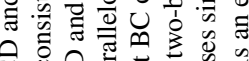

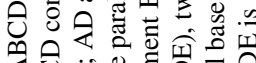

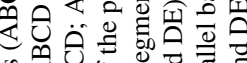

安记

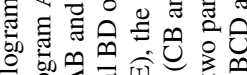

50

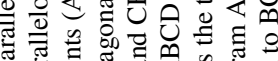

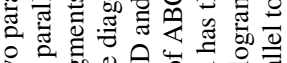

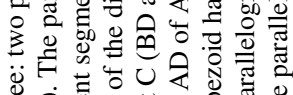

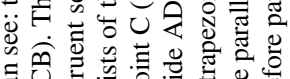

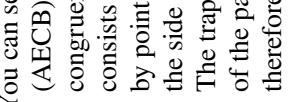

\#

\#

50

的尝

壱 开

的泀

घट ज क

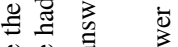

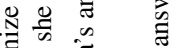

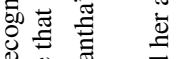

芯䓌

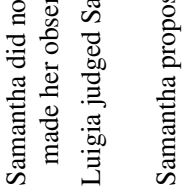

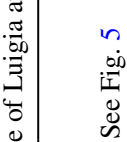

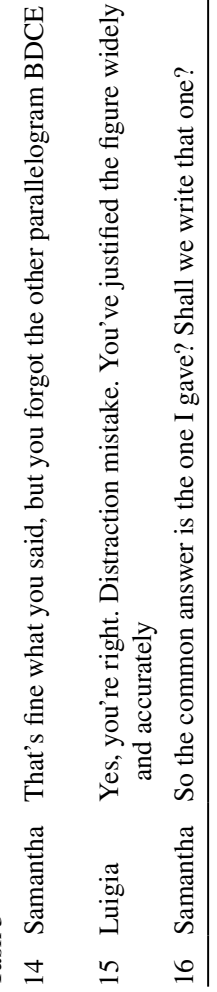




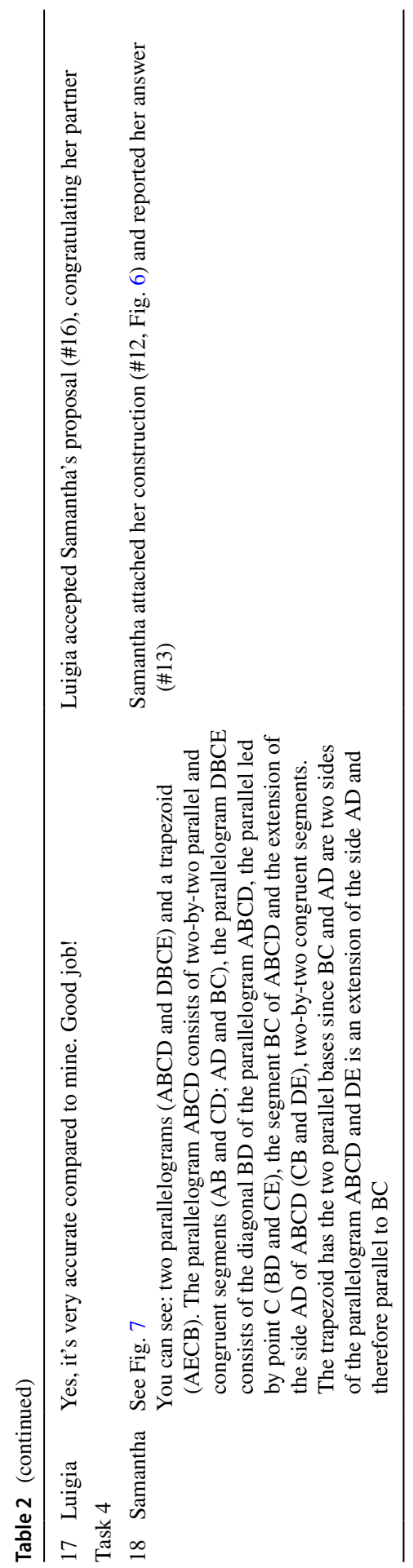


Fig. 5 Luigia's GeoGebra construction

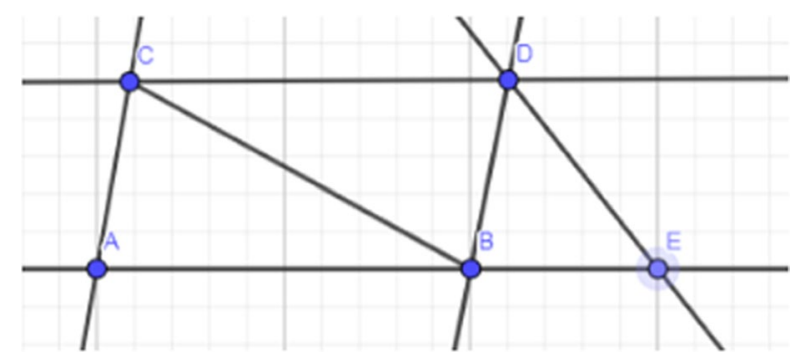

student identified only the two parallelograms (ABCD and BDGC) and not the trapezoid (AGCD). He did not produce arguments to support his answer either.

The following discussion saw Forever33 trying to correct the mistakes made by Conad. First, he brought his partner's attention to the question (shown in bold on \#29), highlighting that the task required the identification of quadrilaterals and not triangles. This led Conad to construct a new figure (\#30, Fig. 12), this one corrected (in which, however, the student did not use letters to indicate points, which he had done in the previous construction at \#25, Fig. 10) and not to consider triangles in his answer (line 31). Then Forever33 (\#32), referring to his figure (\#27, Fig. 11), corrected his partner again, indicating also the occurrence of the scalene trapezoid (AGCD).

Strangely enough, this trapezoid had not been detected even by Forever33 in his individual answer (\#28). It seems, therefore, that, in an attempt to correct his partner, he also reflected on his own answer and, in this way, was able to correct one of his mistakes. In order to be even clearer with his partner, Forever33 attached a new figure (\#33, Fig. 13), modified with respect to the previous

Fig. 6 Samantha GeoGebra construction

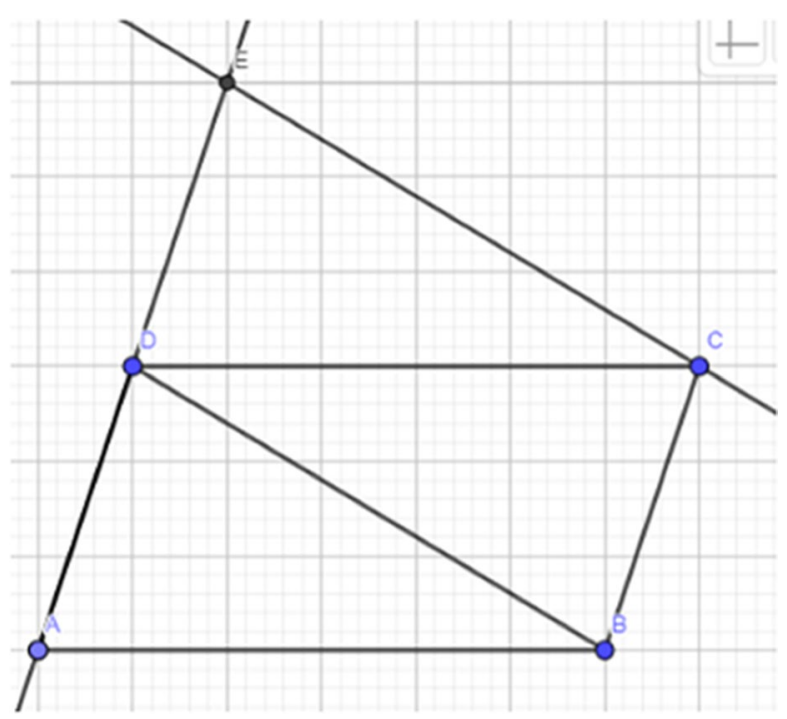


Fig. 7 Luigia and Samantha's construction

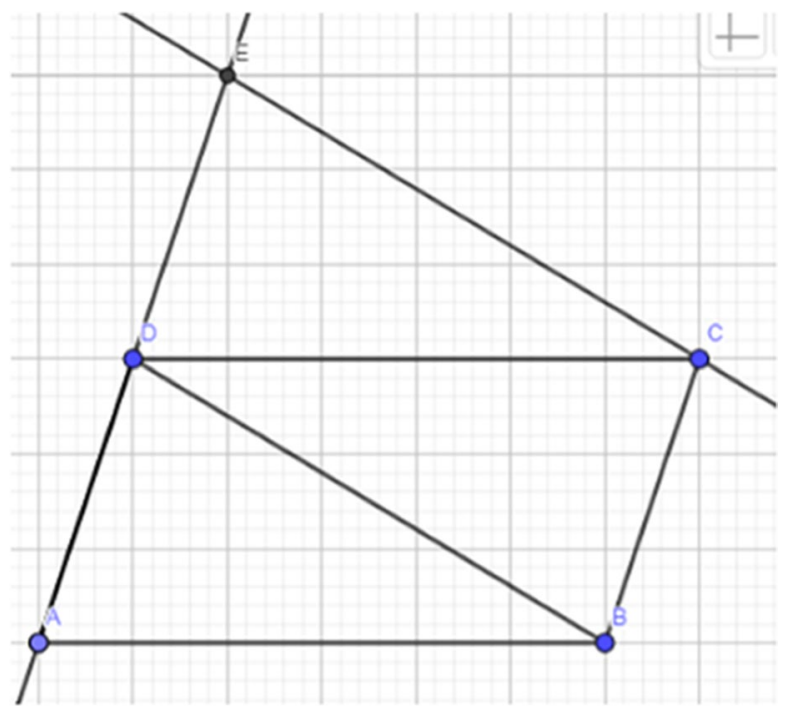

one (\#27, Fig. 11), with the addition of coloured lines (probably using the Paint software available on his PC), in which he highlighted clearly and with different colours the quadrilaterals he identified: the two parallelograms in red and blue respectively, and the scalene trapezoid in black. The discussion with his partner seemed to convince Forever33 that it was not enough to refer to letters and he decided to move on to colours. Conad thought he had made a mistake again and started showing signs of boredom (\#35). Actually, his construction (\#30, Fig. 12) was correct and only the vertices’ labels were missing. However, Conad seemed to think his partner was more experienced and started to imitate him.

So, he constructed a new GeoGebra figure (\#36, Fig. 14), completely different from the previous one, in which he drew the diagonal $\mathrm{BD}$, as required, but then drew the parallel to AC passing through $\mathrm{B}$, probably to imitate the construction of his partner (\#27, Fig. 11, and \#33, Fig. 13). Indeed, the student, in his next answer (\#37), referred to the parallelogram BDGC, which relates to the figure of his partner, because in his figure (\#36, Fig. 14), BDGC does not appear to be a quadrilateral. At this point in the discussion, Forever33 again corrected Conad's answer, indicating the occurrence of the scalene trapezoid (\#38). Conad clearly expressed his boredom (\#39). However, Forever33 (\#40) tried to help his partner understand that the figure needed only minor adjustments and suggested considering the other diagonal.

It is interesting to observe how Forever33, in an attempt to help his partner in the construction of a correct figure, (improperly) used the term bisector (\#40), referring to the diagonal of the parallelogram. This seemed to confirm how this term, also used by Ilenia (\#7 and \#9, Fig. 4), had an ambiguous meaning for the students. There also seemed to be a misconception that bisector divides the angle into two parts that are not necessarily equal. Conad picked up the partner's suggestion (\#41), but refused to modify his figure again. Conad's difficulties in making the figure from the described properties seemed to be too great for him. Then Forever33, acting as 


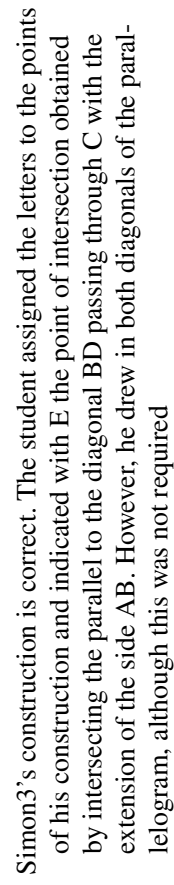

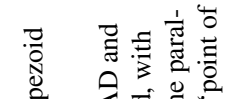

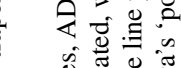

焉

兽

की

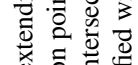

×.

它记

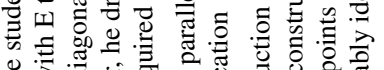

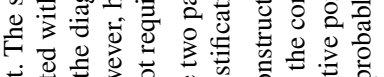

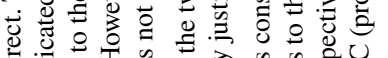

ठ․ㅀ

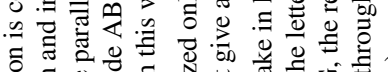

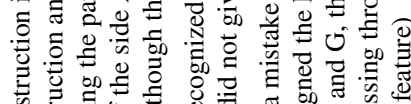

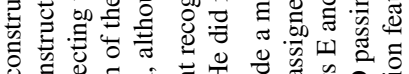

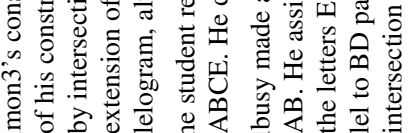

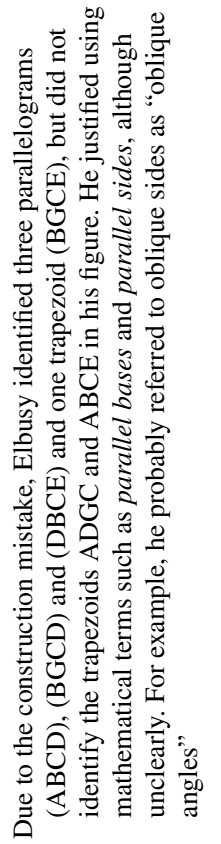

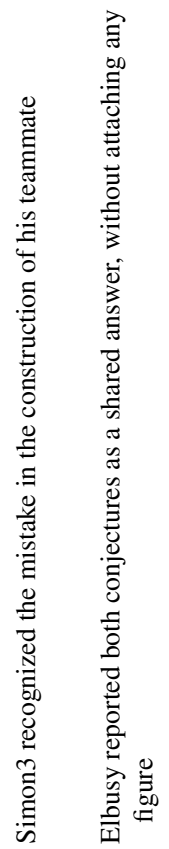

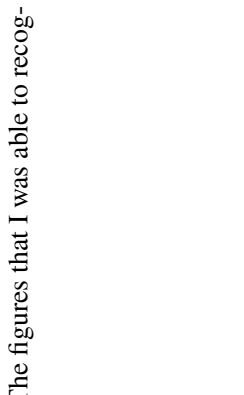

穴导

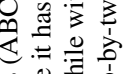

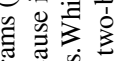

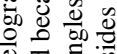

믐

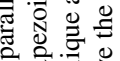

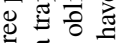

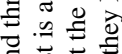

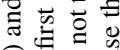

宛

위웛

$\stackrel{2}{D}$

产

苗

월 을

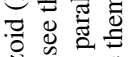

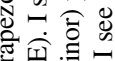

可式

论节芯

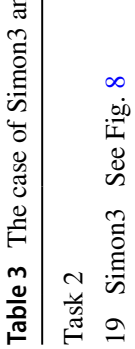

행 웜

\& :

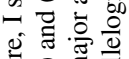

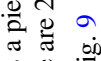

挡语

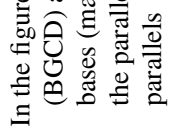

穴导

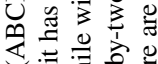

«.

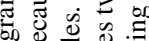

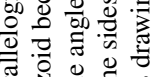

河

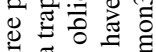

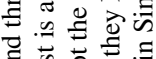

空

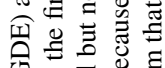

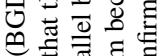

\&

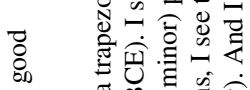

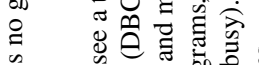

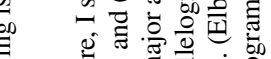

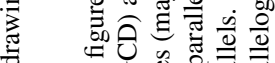

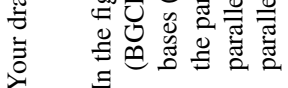

言產

產

구

ป

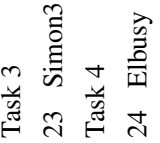


Fig. 8 Simon3's GeoGebra construction

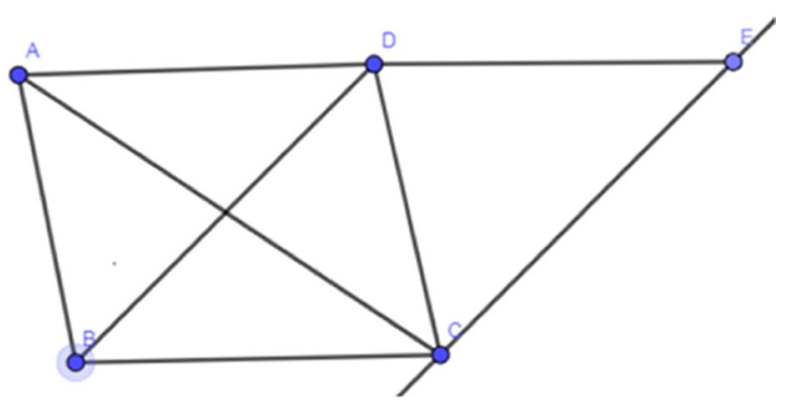

a spokesperson, wrote the 'final conjecture', but without explicit agreement with his partner. He attached two images, namely his construction (\#27, Fig. 11) and a further one obtained by modifying (probably with the Paint software) Conad's last construction (\#36, Fig. 14), eliminating the diagonal BD and drawing in instead the diagonal AC (\#42, Fig. 15). However, the image obtained by modifying that of his partner's is not correct, because the line through B is not parallel to the diagonal BD, as required by the problem, but to the diagonal AC. Apparently, Forever33 edited Conad's construction with the aim of bringing back some trace of the partner work.

The whole discussion concerned the identification of quadrilaterals. At the beginning, Forever33 felt the need to explain the task to his partner who seemed not to understand it well; this seemed to trigger the elaboration both of the figure and of the arguments. He found an extra quadrilateral, tried to describe the figure better and highlighted the mistake made by the partner. However, in the end, the letters disappeared and no justification for the nature of the quadrilateral was elaborated. As in the case of Luigia and Samantha, also (and above all) in this case, the discussion seemed to focus on 'mistakes' and 'assessments' (\#29, \#32, \#33 (Fig. 13), \#34, \#38, \#40). Forever33 seemed to be imitating the teacher's behaviour, while Conad tried to imitate his partner, considering him to be more experienced; nevertheless, no real collaboration occurred and the answer was not elaborated further.

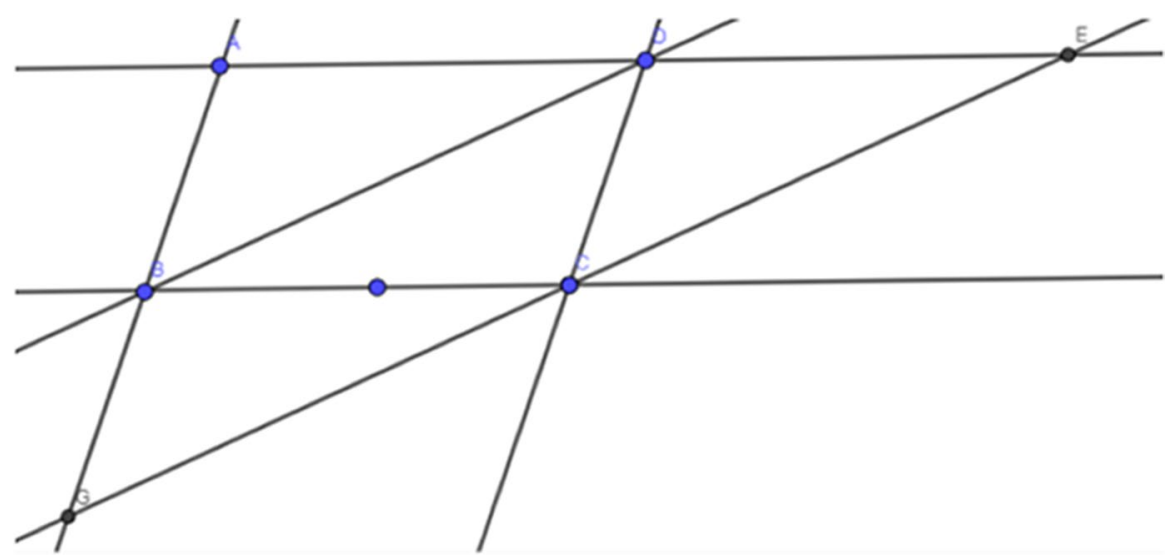

Fig. 9 Elbusy's GeoGebra construction 
Moreover, the explanations provided by Forever33 moved mainly at the perceptual level, aiming at helping Conad 'see' the quadrilateral. These arguments are difficult to translate into a justification text and may be rather irrelevant to communicate to the teacher-who would read the answer - and who certainly could see the quadrilaterals. What seems interesting is the fact that the effort to explain did not evolve into a geometrical justification, possibly because of the lack of motivation to overcome the perceptual control towards the geometrical control.

\section{Discussion and Conclusions}

In this article, I investigated the educational potential of a digital environment to support students in moving from the production of conjectures to the construction of mathematical proofs. In particular, I analyzed a specific work area, called 'Working with others', designed as a collaborative script (King, 2007; Weinberger et al., 2009). The students worked in pairs and first, individually, they constructed a GeoGebra figure (Task 1) and solved an open problem (Task 2). Then they discussed within the group (Task 3 ) to formulate a shared answer and its justification (Task 4). Students involved in the experiment were not used to collaborating in class with peers and were rarely involved in argumentative activity. They were familiar with GeoGebra, but not with online platforms.

My research question was as follows: to what extent is the 'Working with others' area, by stimulating collaboration and comparison within the group, able, on its own, to promote the production of mathematically acceptable arguments, produced in a collaborative and sharing mode? In all the cases analyzed, the discussion within the group (Task 3) seemed to help students understand the mistakes made, but more in relation to the GeoGebra construction and not as much regarding the justification of the conjectures produced. The qualitative analysis of the data, therefore, seems to give us a negative answer to my research question. The 'Working with others' area, despite integrating epistemic (Tasks 1 and 2) and social script components (Task 3) (Weinberger \& Fischer, 2006), seems not to have favoured an improvement in the production of mathematically acceptable arguments, as results of a collaborative and sharing mode. The students' idea of 'agreeing' seemed to concern, at most, the choice of the best answer (e.g. the case of Luigia and Samantha) rather than the production of a co-constructed text. Sometimes, without a real agreement within the group, one of the students reported her own as a shared answer (e.g. the case of Conad and Forever33). At other times, both answers, produced individually (e.g. the case of Simon3 and Elbusy), were reported.

Students rarely produced a new shared text. This happened in the case of Ilenia and Claudia, but, in their shared answer, useful information provided by the students in their individual arguments was missed, as if, in the negotiation of the text, some of the unshared elements were considered irrelevant. Sometimes, students chose different strategies to help their partner, such as Forever33, who opted to use perceptual arguments, i.e. colours (\#33, Fig. 13, and \#34). However, the collaboration did not move towards involving theoretical arguments, as I would have liked. The students seemed to work on the epistemic dimension (they responded to the task) and on the 
dimension of social modes of co-construction (in most cases, they discussed within the group), but not very much on the argument one. They were not accustomed to argue in class and the support provided by the digital environment, while favouring the production of texts through peer interaction, was not enough to foster the production of mathematically acceptable arguments.

However, there is another aspect that needs to be highlighted. As already pointed out, the students were not used to collaborating and this also emerged from the analysis of their discussions. It seemed that the students often turned to their partner imitating the teacher's behaviour (for example, the case of Luigia and Samantha, but even more so that of Forever33 and Conad): their answers often seemed to be focused on identifying possible mistakes and judging the 'accuracy' of the partner's answer, and in this can be recognized a teacher's typical assessment behaviour. Sometimes students tried to imitate the partner considered more experienced, as in the case of Conad and Forever33. On the other hand, the more expert student often felt authorized to explain, to help the partner, but it was not a real collaboration aimed at producing a shared answer.

The results of this study are in agreement with those shown by Kynigos and Theodosopoulou (2001). The two researchers described a study in which Greek students worked in small groups in computer-based classroom activities. The social interaction among students was not of high quality and the authors tried to identify the most resistant obstacles to the development of social modes of learning. They observed that social exchanges, even if they did take place, were not at all at the heart of the students' intentions and were often treated as a secondary issue. Moreover, the social norms that emerged within the group and the classroom were judgmental.

In summary, the 'Working with others' area, analyzed in this article, seemed to favour the discussion within the group and to be able to make students aware of the mistakes made - for example, in the construction or identification of figures. Moreover, students, in an attempt to correct their partner's mistakes, sometimes recognized their own, as in the case of Forever33 (Table 4, \#32). The activity may even bring out students' misconceptions, such as in the case of bisector (Table 1, \#7 and \#9, Fig. 4; Table 4, \#40), considered by some students as a straight line that divides the angle into two parts, though not necessarily equal. In this respect, the outcome of student activity in this environment could provide useful information upon which the teacher might trigger fruitful collective discussions according to her didactic goal. However, the 'Working with others' area seemed not to foster significant improvement in the production of mathematically acceptable arguments produced by students in collaborative mode.

\section{Future Perspectives}

The results of this study made me deepen my reflection on one of its key elements and ask myself: what is really meant by collaboration? How does it work? What specific hypotheses can lead us to say whether a collaborative script can trigger an effective collaborative process concerning the development of 


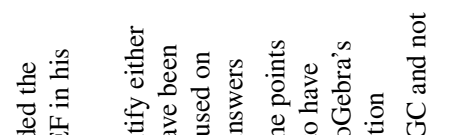

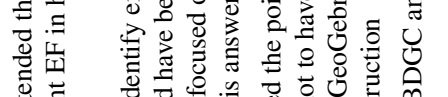

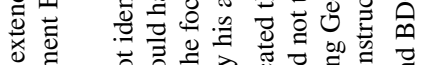

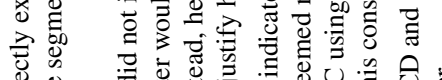

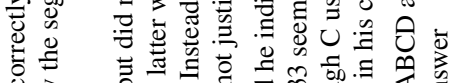

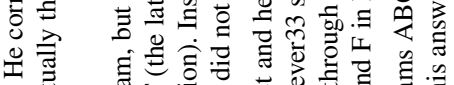

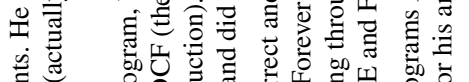

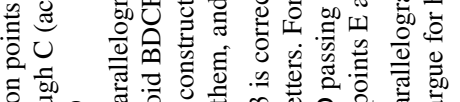

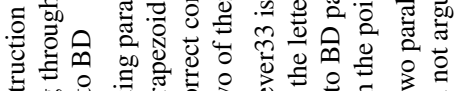

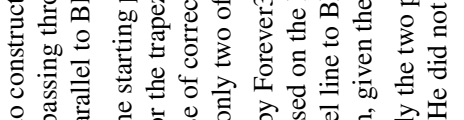

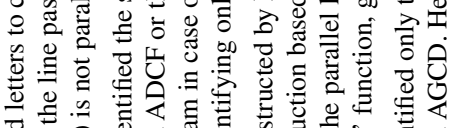

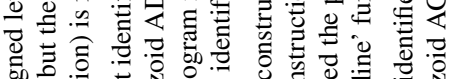

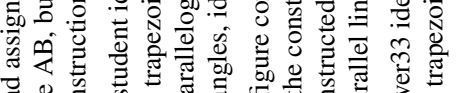

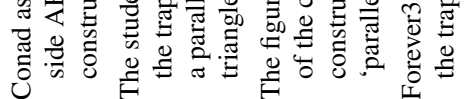
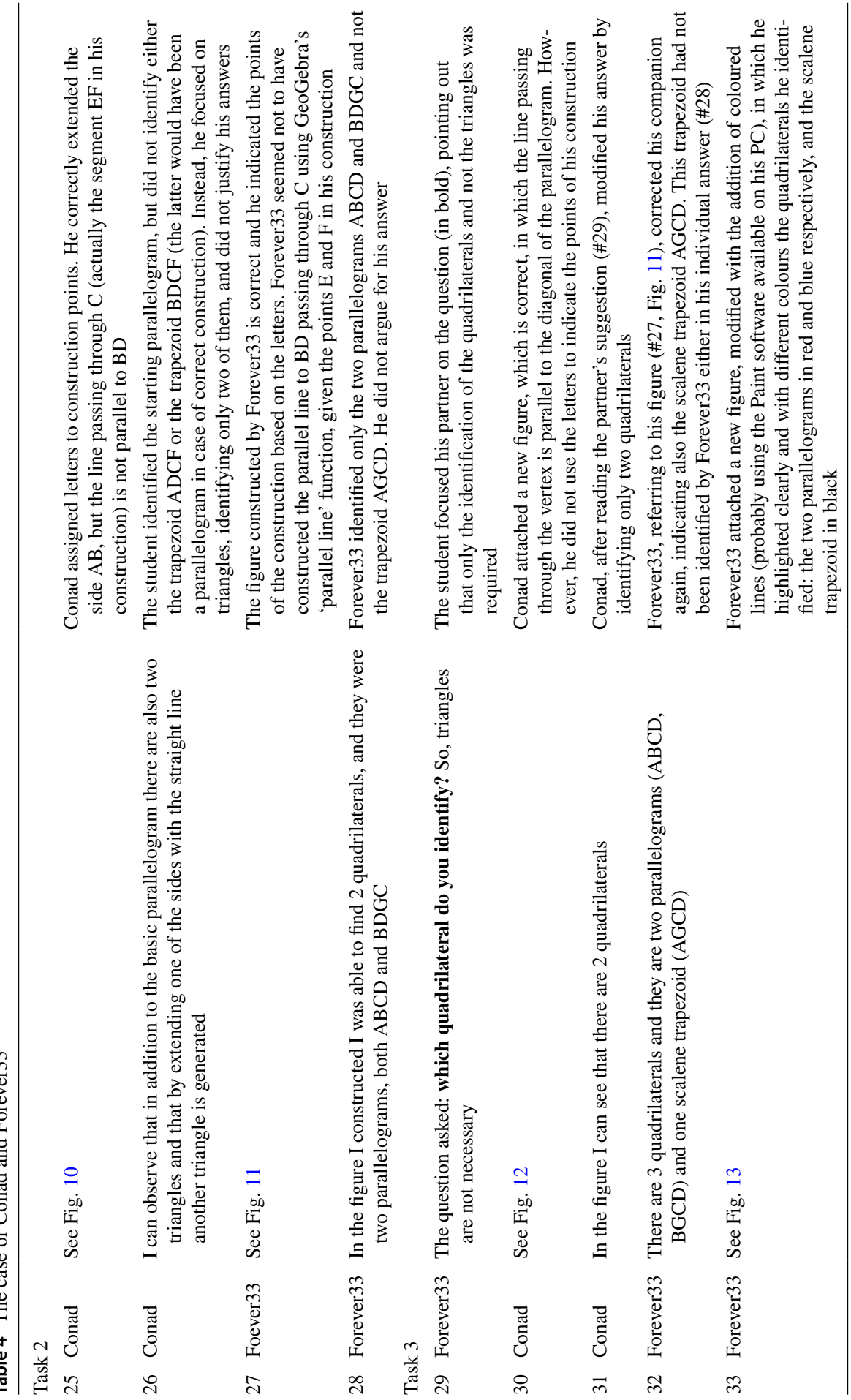

:
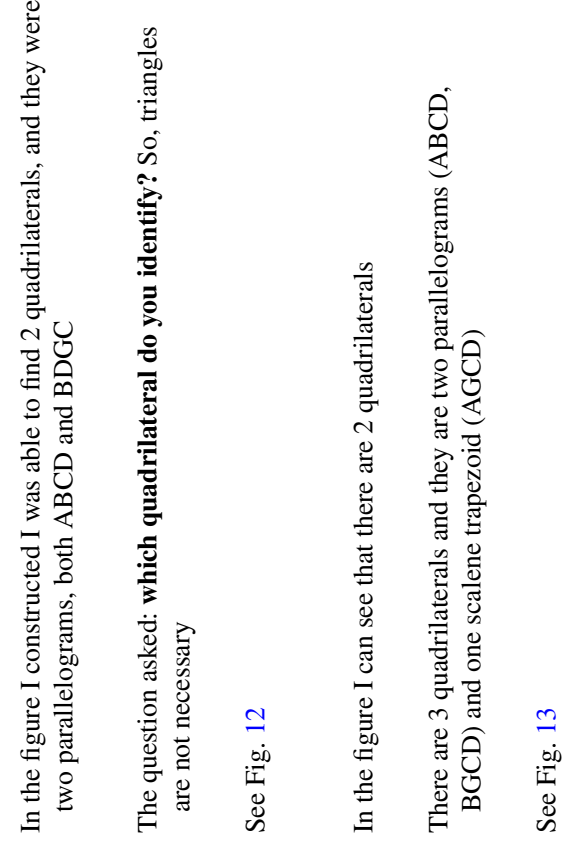

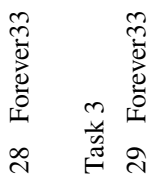

氶

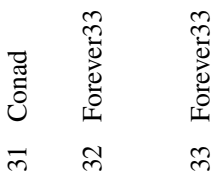




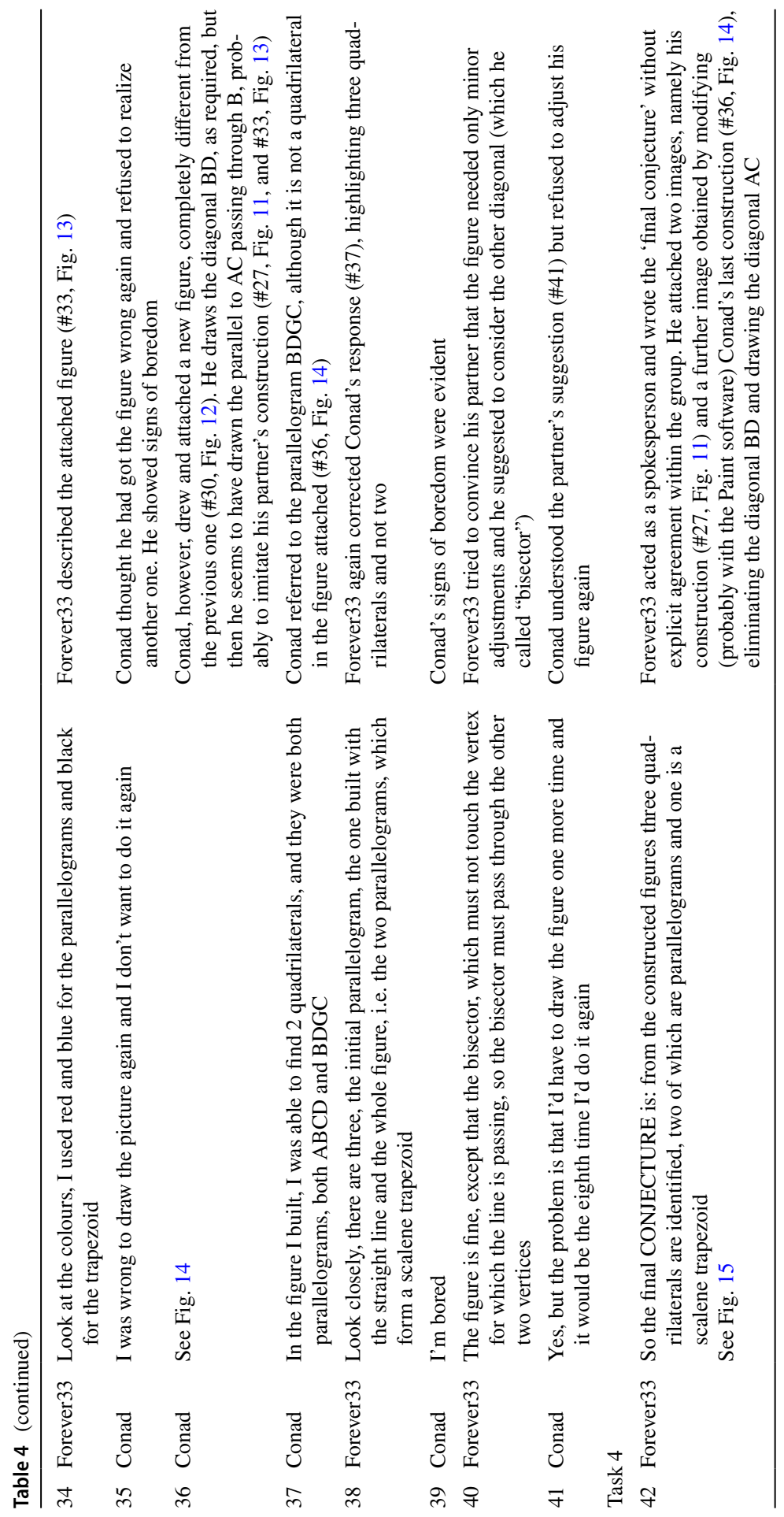


Fig. 10 Conad's GeoGebra construction

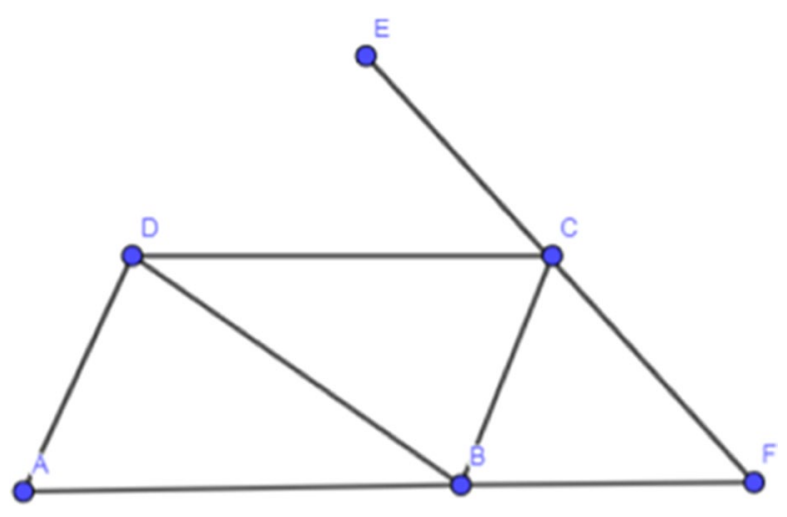

mathematically advanced arguments? Which of the things observed and reported on above make us hypothesize that a student, before starting collaborative activities mediated by an external script, may already have internalized an internal script, concerning key aspects of collaboration? This means that students should already have an idea of how to behave during the collaboration between classmates, regarding the resolution of tasks, and, specifically, a mathematical task. Assuming that students already have knowledge about how to act in collaborative learning, i.e. they already have an internal collaborative script (Kollar et al., 2006), an adequate integration between the external and internal script is necessary to foster the development of (argumentative) skills (Carmien et al., 2007). In the case described, this hypothesis seems not to be fulfilled, i.e. students did not seem to have an internal script for collaborative learning. This can strongly influence the success or failure of the collaborative learning activity. In future research work, it will be interesting to investigate this. Also, it will be interesting to understand the nature of students' mathematical thinking while communicating with their peers.

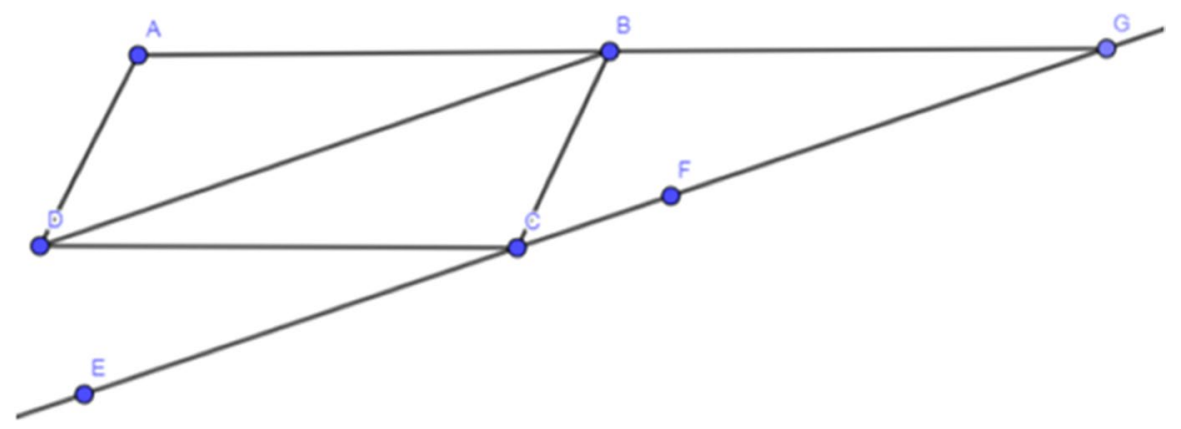

Fig. 11 Foever33's GeoGebra construction 
Fig. 12 Conad's new construction

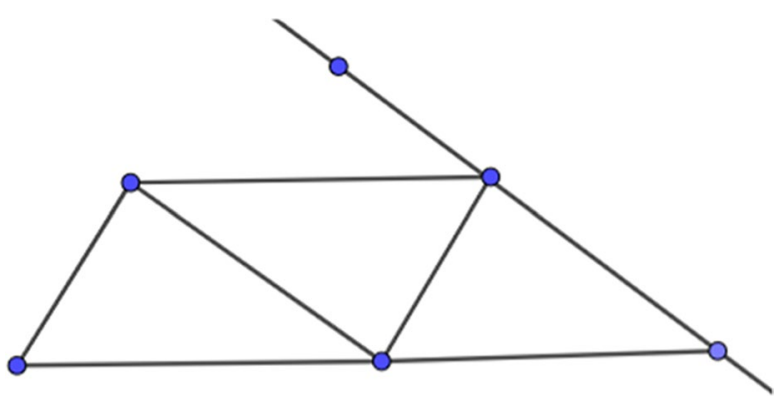

My results show the limits in fostering collaboration towards the construction of a shared answer, in particular in triggering a discussion on the need of arguments supporting the answer and on the mathematical adequacy of such arguments. In this regard, as already mentioned, in order to empower the argumentative script component in supporting the move from arguments expressed in colloquial registers to literate ones, within the 'Working alone' and 'Working alone and with others' areas, we integrated a device which we named Digital Toolkit for Proof (DTP) (Albano et al., 2021). The DTP device is an application implemented with GeoGebra software and integrated within an online platform (e.g. Moodle), which allows the student to access simultaneously:

several digital tiles representing different language elements (nouns, propositions, conjunctions which she can manipulate and drag in order to express her own conjecture or its proof;

other fixed, non-draggable, digital tiles, which compose the 'Bank of Theory', i.e. the theoretical elements (definitions, properties and theorems) that she can refer in order to prove her claim.

In accordance with design principle P2, the availability of language tiles and, above all, of the theoretical elements contained in the 'Bank of Theory', are expected to foster the move from colloquial registers to literate ones (Ferrari, 2004), and, consequently, to the production of formally acceptable arguments.

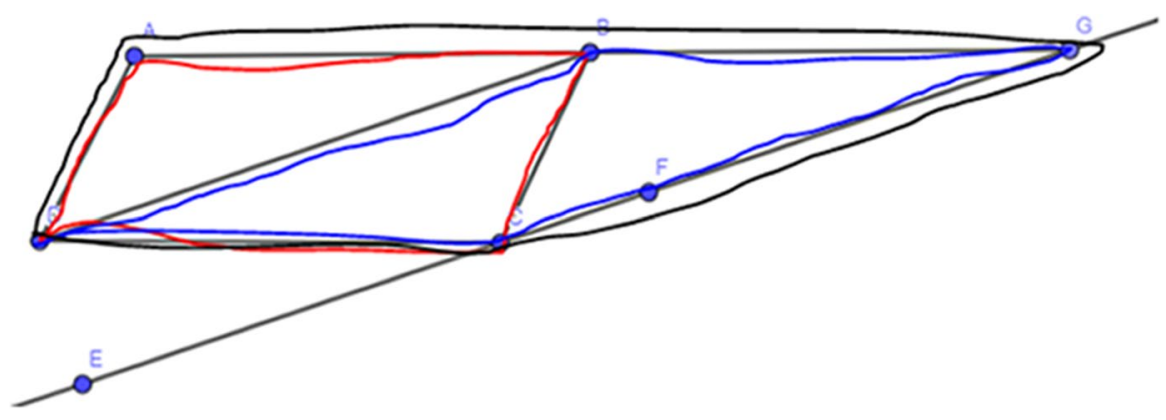

Fig. 13 Forever33's figure with coloured lines 


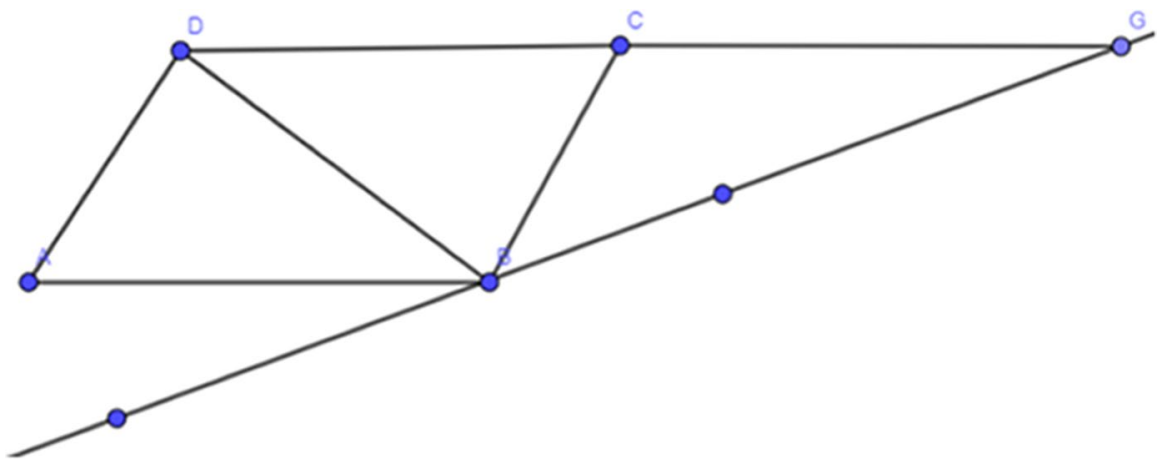

Fig. 14 Conad's other construction

In this direction, I expect that new light will be shaded from the exploration of the 'Working alone and with others' area. According to the design, in this area, all the essential script dimensions (i.e. the epistemic dimension, the argument dimension and the dimension of social modes of co-construction) are involved. Indeed, the 'Working alone and with others' area combines both specific features of the 'Working alone' area (in particular, it integrates the DTP device as an argumentative script component) and those of the 'Working with others' area (i.e.

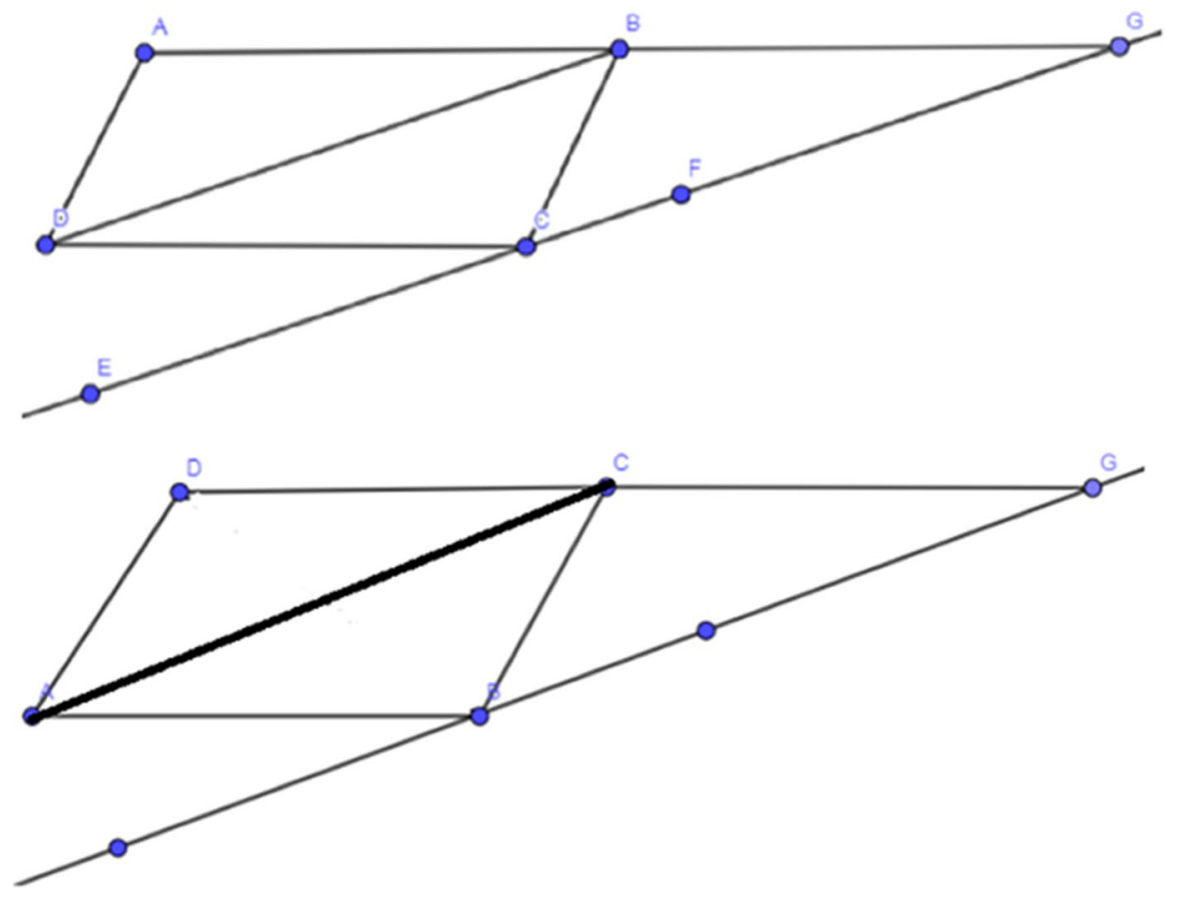

Fig. 15 Conad's other construction 
social script components of co-construction). I expect that the tasks developed in this area both promote collaboration and support the move from argumentation to proof. This will be the objective for a future research project.

Acknowledgements I thank the teachers Carlo Celoro, Donatella Roberto, Antonella Maffei (IISS "Umberto Nobile - Roald Amundsen", Lauro, Italy) and Raffaella Ferrara (ISISS "De Luca", Avellino, Italy) and their students, who participated to the experimentation.

Funding Open access funding provided by Università degli Studi della Campania Luigi Vanvitelli within the CRUI-CARE Agreement. This research is supported by grants of the University of Campania 'Luigi Vanvitelli', in the frameworks of V:ALERE 2019 (GoAL project) and V:ALERE 2020 (LIME project).

\section{Declarations}

Conflict of Interest The author declares no competing interests.

Open Access This article is licensed under a Creative Commons Attribution 4.0 International License, which permits use, sharing, adaptation, distribution and reproduction in any medium or format, as long as you give appropriate credit to the original author(s) and the source, provide a link to the Creative Commons licence, and indicate if changes were made. The images or other third party material in this article are included in the article's Creative Commons licence, unless indicated otherwise in a credit line to the material. If material is not included in the article's Creative Commons licence and your intended use is not permitted by statutory regulation or exceeds the permitted use, you will need to obtain permission directly from the copyright holder. To view a copy of this licence, visit http://creativecommons.org/licen ses/by/4.0/.

\section{References}

Albano, G., \& Dello Iacono, U. (2018). Scripting collaboration for competence-based mathematics learning. In J. Silverman \& V. Hoyos (Eds.), Distance learning, e-learning and blended learning of mathematics (pp. 115-131). Springer.

Albano, G., \& Dello Iacono, U. (2019a). GeoGebra in e-learning environments: A possible integration in mathematics and beyond. Journal of Ambient Intelligence and Humanized Computing, 10(11), $4331-4343$.

Albano, G., \& Dello Iacono, U. (2019b). A scaffolding toolkit to foster argumentation and proofs in mathematics: Some case studies. International Journal of Educational Technology in Higher Education, 16(1), \#4, (12).

Albano, G., Dello Iacono, U., \& Mariotti, M. (2019). A computer-based environment for argumenting and proving in geometry. In U. Jankvist, M. van den Heuvel-Panhuizen \& M. Veldhuis (Eds), Proceedings of the Eleventh Congress of the European Society for Research in Mathematics Education (pp. 729-736). Freudenthal Group \&Freudenthal Institute, Utrecht University and ERME.

Albano, G., Dello Iacono, U., \& Mariotti, M. (2021). An e-learning innovative approach for mathematical argumentative thinking. The International Journal for Technology in Mathematics Education, 28(1), $3-14$.

Anderson, J., Boyle, C., \& Yost, G. (1986). Using computers to teach: The geometry tutor. The Journal of Mathematical Behavior, 5(1), 5-19.

Anderson, J., Corbett, A., Koedinger, K., \& Pelletier, R. (1995). Cognitive tutors: Lessons learned. Journal of the Learning Sciences, 4(2), 167-207.

Andriessen, J., Baker, M., \& Suthers, D. (Eds.). (2003). Arguing to learn. Confronting cognitions in computer-supported collaborative learning environments. Kluwer Academic Publishers.

Arsac, G., Germain, G., \& Mante, M. (1991). Problèmeouvert et situation-problème. IREM. 
Arzarello, F., Drijvers, P., \& Thomas, M. (2012). How representation and communication infrastructures can enhance mathematics teacher training. Paper presented at the 12th International Congress on Mathematical Education. COEX.

Baker, M. (2003). Computer-mediated argumentative interactions for the co-elaboration of scientific notions. In J. Andriessen, M. Baker, \& D. Suthers (Eds.), Arguing to learn: Confronting cognitions in computer-supported collaborative learning environments (pp. 47-78). Kluwer Academic Publishers.

Balacheff, N. (1988). Une étude de processus de preuveenmathématiques chez élèves de Collège. Thèse de Doctoratd'Etat. Université Joseph Fourier.

Boero, P., Garuti, R., \& Mariotti, M. (1996). Some dynamic mental processes underlying producing and proving conjectures. In L. Puig \& A. Gutiérrez (Eds), Proceedings of the $20^{\text {th }}$ Conference of the International Group for the Psychology of Learning Mathematics (vol. 2, pp. 121-128). Universitat de Valencia and PME.

Boero, P., Garuti, R., \& Lemut, E. (1999). About the generation of conditionality of statements and its links with proving. In O. Zaslavsky (Ed.), Proceedings of the $23^{\text {rd }}$ Conference of the International Group for the Psychology of Learning Mathematics (vol. 2, pp. 137-144). PME.

Borba, M., Askar, P., Engelbrecht, J., Gadanidis, G., Llinares, S., \& Aguilar, M. (2016). Blended learning, e-learning and mobile learning in mathematics education. ZDM: The International Journal on Mathematics Education, 48(5), 589-610.

Carmien, S., Kollar, I., Fischer, G., \& Fischer, F. (2007). The interplay of internal and external scripts: A distributed cognition perspective. In F. Fischer, H. Mandl, J. Haake, \& I. Kollar (Eds.), Scripting computer-supported collaborative learning: Cognitive, computational, and educational perspectives (pp. 303-326). Springer.

Cerulli, M., Pedemonte, B., \& Robotti, E. (2005). An integrated perspective to approach technology in mathematics education. In M. Bosch (Ed.), Proceedings of the Fourth Congress of the European Society for Research in Mathematics Education (pp. 1389-1399). FUNDEMI IQS - Universitat Ramon Llull andERME.

Chevallard, Y., \& Ladage, C. (2009). E-learning as a touchstone for didactic theory, and conversely. Journal of E-Learning and Knowledge Society, 4(2), 163-171.

Chi, M., Bassok, M., Lewis, M., Reimann, P., \& Glaser, R. (1989). Self-explanations: How students study and use examples in learning to solve problems. Cognitive Science, 13(2), 145-182.

de Villiers, M. (2004). Using dynamic geometry to expand mathematics teachers' understanding of proof. International Journal of Mathematical Education in Science and Technology, 35(5), $703-724$.

Drijvers, P. (2012). Teachers transforming resources into orchestrations. In G. Gueudet, B. Pepin, \& L. Trouche (Eds.), From text to 'lived' resources: Mathematics curriculum materials and teacher development (pp. 265-281). Springer.

Duval, R. (1991). Structure du raisonnementdéductif et apprentissage de la démonstration. Educational Studies in Mathematics, 22(3), 233-261.

Duval, R. (1995). Quelcognitifretenirendidactique des mathématiques? RecherchesenDidactique Des Mathématiques, 16(3), 349-382.

Ferrari, P. (2004). Mathematical language and advanced mathematics learning. In M. JohnsenHøines\& A. Fuglestad (Eds). Proceedings of the 28th Conference of the International Group for the Psychology of Mathematics Education (vol. 2, pp. 383-390). PME.

Freudenthal, H. (1973). Mathematics as an educational task. D. Reidel Publishing Company.

Fujita, T., Doney, J., \& Wegerif, R. (2019). Students' collaborative decision-making processes in defining and classifying quadrilaterals: A semiotic/dialogic approach. Educational Studies in Mathematics, 101(3), 341-356.

Hadas, N., Hershkowitz, R., \& Schwarz, B. (2000). The role of contradiction and uncertainty in promoting the need to prove in dynamic geometry environments. Educational Studies in Mathematics, 44(1-3), 127-150.

Halliday, M. (1985). An introduction to functional grammar. Edward Arnold.

Hanna, G. (2014). The width of a proof. PNA: Revista de Investigación en Didáctica de la Matemática, 9(1), 29-39.

Hoyles, C., \& Jones, K. (1998). Proof in dynamic geometry contexts. In C. Mammana \& V. Villani (Eds.), Perspectives on the teaching of geometry for the 21st century (pp. 121-128). Kluwer Academic Publishers. 
King, A. (2007). Scripting collaborative learning processes: A cognitive perspective. In F. Fischer, I. Kollar, H. Mandl, \& J. Haake (Eds.), Scripting computer-supported collaborative learning: Cognitive, computational and educational perspectives (pp. 13-37). Springer.

Kollar, I., Fischer, F., \& Hesse, F. (2006). Collaboration scripts: A conceptual analysis. Educational Psychology Review, 18(2), 159-185.

Kuhn, D., Shaw, V., \& Felton, M. (1997). Effects of dyadic interaction on argumentative reasoning. Cognition and Instruction, 15(3), 287-315.

Kynigos, C., \& Theodosopoulou, V. (2001). Synthesizing personal, interactionist and social norms perspectives to analyze student communication in a computer-based mathematical activity in the classroom. Journal of Classroom Interaction, 36(2), 63-73.

Laborde, C. (2000). Dynamic geometry environments as a source of rich learning contexts for the complex activity of proving. Educational Studies in Mathematics, 44(1-2), 151-161.

Laurillard, D. (2013). Teaching as a design science: Building pedagogical patterns for learning and technology. Routledge.

Lazarou, D., Sutherland, R., \& Erduran, S. (2016). Argumentation in science education as a systemic activity: An activity-theoretical perspective. International Journal of Educational Research, 79, $150-166$.

Leitão, S. (2000). The potential of argument in knowledge building. Human Development, 43(6), 332-360.

Mandl, H., Gruber, H., \& Renkl, A. (1996). Communities of practice toward expertise: Social foundation of university instruction. In P. Baltes \& U. Staudinger (Eds.), Interactive minds: Life-span perspectives on the social foundation of cognition (pp. 394-411). Cambridge University Press.

Mariotti, M. (2006). Proof and proving in mathematics education. In A. Gutiérrez \& P. Boero (Eds.), Handbook of research on the psychology of mathematics education: Past, present and future (pp. 173-204). Sense Publishers.

Mariotti, M., \& Fischbein, E. (1997). Defining in classroom activities. Educational Studies in Mathematics, 34(3), 219-248.

Mariotti, M., Bartolini Bussi, M., Boero, P., Ferri, F., \& Garuti, R. (1997). Approaching geometry theorems in contexts: From history and epistemology to cognition. In E. Pehkonen (Ed.), Proceedings of the $21^{\text {st }}$ Conference of the International Group for the Psychology of Learning Mathematics (vol. 1, 180-195). PME.

Mariotti, M., Durand-Guerrier, V., \& Stylianides, G. (2018). Argumentation and proof. In T. Dreyfus, M. Artigue, D. Potari, S. Prediger, \& K. Ruthven (Eds.), Developing research in mathematics education: Twenty years of communication, co-operation and collaboration in Europe (pp. 75-89). Routledge.

Marttunen, M., \& Laurinen, L. (2001). Learning of argumentation skills in networked and face-toface environments. Instructional Science, 29(2), 127-153.

Miyazaki, M., Fujita, T., Jones, K., \& Iwanaga, Y. (2017). Designing a web-based learning support system for flow-chart proving in school geometry. Digital Experiences in Mathematics Education, 3(3), 233-256.

Moore, R. (1994). Making the transition to formal proof. Educational Studies in Mathematics, 27(3), 249-266.

NCTM. (2000). Principles and standards for school mathematics. National Council of Teachers of Mathematics.

Pedemonte, B. (2002). Étude didactique et cognitive des rapports de l'argumentation de la démonstrationenmathématiques. Thèse de Doctorat. Université Joseph Fourier.

Pedemonte, B. (2007). How can the relationship between argumentation and proof be analysed? Educational Studies in Mathematics, 66(1), 23-41.

Pedemonte, B. (2008). Argumentation and algebraic proof. ZDM: The International Journal on Mathematics Education, 40(3), 385-400.

Schank, R., \& Abelson, R. (1977). Scripts, plans, goals and understandings. Lawrence Erlbaum Associates.

Sinclair, N., \& Robutti, O. (2012). Technology and the role of proof: The case of dynamic geometry. In A. Bishop, K. Clement, C. Keitel, J. Kilpatrick, \& F. Leung (Eds.), Third international handbook of mathematics education (pp. 571-596). Springer.

Sinclair, N., BartoliniBussi, M., de Villiers, M., Jones, K., Kortenkamp, U., Leung, A., \& Owens, K. (2016). Recent research on geometry education: An ICME-13 survey team report. ZDM: The International Journal on Mathematics Education, 48(5), 691-719. 
Stegmann, K., Weinberger, A., \& Fischer, F. (2007). Facilitating argumentative knowledge construction with computer-supported collaboration scripts. International Journal of Computer-Supported Collaborative Learning, 2(4), 421-447.

Stylianides, A., Bieda, K., \& Morselli, F. (2016). Proof and argumentation in mathematics education. In A. Gutiérrez, G. Leder, \& P. Boero (Eds.), The second handbook of research on the psychology of mathematics education (pp. 315-351). Sense Publishers.

Trouche, L., \& Drijvers, P. (2014). Webbing and orchestration: Two interrelated views on digital tools in mathematics education. Teaching Mathematics and Its Applications, 33(3), 193-209.

Vygotsky, L. (1980). Mind in society: The development of higher psychological processes. Harvard University Press.

Weinberger, A., \& Fischer, F. (2006). A framework to analyze argumentative knowledge construction in computer-supported collaborative learning. Computers \& Education, 46(1), 71-95.

Weinberger, A., Stegmann, K., Fischer, F., \& Mandl, H. (2007). Scripting argumentative knowledge construction in computer-supported learning environments. In F. Fischer, I. Kollar, H. Mandl, \& J. Haake (Eds.), Scripting computer-supported collaborative learning (pp. 191-211). Springer.

Weinberger, A., Kollar, I., Dimitriadis, Y., Mäkitalo-Sieg1, K., \& Fischer, F. (2009). Computer-supported collaboration scripts: Perspectives from educational psychology and computer science. In N. Balacheff, S. Ludvigsen, T. de Jong, A. Lazonder, \& S. Barness (Eds.), Technology-enhanced learning (pp. 155-173). Springer.

Xiao, J., Wang, M., Jiang, B., \& Li, J. (2018). A personalized recommendation system with combinational algorithm for online learning. Journal of Ambient Intelligence and Humanized Computing, $9(3), 667-677$.

Publisher's Note Springer Nature remains neutral with regard to jurisdictional claims in published maps and institutional affiliations. 